Review

\title{
The Pore-Forming Haemolysins of Bacillus Cereus: A Review
}

\section{Nalini Ramarao * and Vincent Sanchis}

INRA, UMR 1319 MICALIS-AgroParisTech, La Minière, Guyancourt 78280, France;

E-Mail: vincent.sanchis@jouy.inra.fr

* Author to whom correspondence should be addressed; E-Mail: nalini.ramarao@jouy.inra.fr; Tel.: +33-1-3083-36-36; Fax: +33-1-3043-80-97.

Received: 28 February 2013; in revised form: 22 May 2013 / Accepted: 24 May 2013 /

Published: 7 June 2013

\begin{abstract}
The Bacillus cereus sensu lato group contains diverse Gram-positive spore-forming bacteria that can cause gastrointestinal diseases and severe eye infections in humans. They have also been incriminated in a multitude of other severe, and frequently fatal, clinical infections, such as osteomyelitis, septicaemia, pneumonia, liver abscess and meningitis, particularly in immuno-compromised patients and preterm neonates. The pathogenic properties of this organism are mediated by the synergistic effects of a number of virulence products that promote intestinal cell destruction and/or resistance to the host immune system. This review focuses on the pore-forming haemolysins produced by B. cereus: haemolysin I (cereolysin O), haemolysin II, haemolysin III and haemolysin IV (CytK). Haemolysin I belongs to the cholesterol-dependent cytolysin (CDC) family whose best known members are listeriolysin $\mathrm{O}$ and perfringolysin $\mathrm{O}$, produced by L. monocytogenes and C. perfringens respectively. HlyII and CytK are oligomeric ß-barrel pore-forming toxins related to the $\alpha$-toxin of $S$. aureus or the $\beta$-toxin of $C$. perfringens. The structure of haemolysin III, the least characterized haemolytic toxin from the B. cereus, group has not yet been determined.
\end{abstract}

Keywords: $B$. cereus; haemolysins; cereolysin O; haemolysin II; haemolysin III; cytotoxin K; PlcR 


\section{Introduction}

The Bacillus cereus sensu lato group contains diverse Gram-positive spore-forming bacteria that are widespread in the environment. This group comprises seven closely related species: B. mycoides, B. pseudomycoides, B. weihenstephanensis, B. anthracis, B. thuringiensis, B. cytotoxicus and $B$. cereus sensu stricto [1]. Comparisons of genome sequence similarity between species have highlighted the close relationships between these bacteria, making their identification to species level difficult. Contrary to B. subtilis, which is considered as a true soil saprophyte, the metabolic potential of $B$. cereus species is poorly suited for the degradation of plant material, or to metabolize a range of complex carbohydrate polymers. Indeed, the functions of the genes for complex carbohydrate metabolism seems to be limited to the degradation of glycogen, starch, chitin and chitosan, all of which are important components of insect tissues. Furthermore, B. cereus appears to contain many protease genes and many peptide and amino-acid transporter genes. Together, these observations indicate that $B$. cereus is better adapted to a protein diet and that its primary source of nutrients is probably animal tissues [2].

A new genetic structure of the entire $B$. cereus group has recently been proposed. This phylogenetic taxonomy separates the strains into seven groups (I to VII), principally on the basis of their ability to grow at various temperatures [1]. However, not all the bacterial species within a given genetic group have the same capacity to induce disease, and the distinction between pathogenic and innocuous strains is far from clear, for the entire B. cereus group [3]. Moreover, the genetic determinants of $B$. thuringiensis and $B$. anthracis pathogenicity are located on plasmids, which can be exchanged between the various group members, transforming $B$. cereus into B. thuringiensis or B. anthracis through simple plasmid acquisition. Other than these specific plasmid genes, the genomes of the three species, B. anthracis, B. thuringiensis and B. cereus, are very similar, and the genetic determinants required for non-species-specific aspects of infection may be common to all the bacteria of the $B$. cereus group $[2,4]$.

$B$. cereus sensu stricto, or $B$. cereus as it is usually called, is an emerging human pathogen that causes gastroenteritis and is now considered the third most important cause of collective food poisoning incidents in Europe, after Salmonella and Staphylococcus aureus [5]. In 2008, 102 confirmed outbreaks of food borne disease caused by B. cereus were identified by the European community, corresponding to more than a thousand patients [5]. However, B. cereus food borne illness incidents are probably largely under-reported, as the reporting of $B$. cereus food borne poisoning is not mandatory. B. cereus causes two types of food borne illnesses. In both types, the symptoms usually last less than $24 \mathrm{~h}$, but several fatal cases of bloody diarrhoea and emetic poisoning have been reported, mainly in older and debilitated persons [6-11]. The "short-incubation" or emetic form, with symptoms similar to those of $S$. aureus infections, is caused by the ingestion of cereulide, a peptide produced by the bacterium and already present in the ingested food [12]. This small molecule is believed to bind to 5-hydroxytryptamine 3 (5-HT3) receptors causing vomiting and acts like an ionophore leading to inhibition of mitochondrial activity. The "long-incubation" or diarrhoeal form, which resembles the food poisoning caused by Clostridium perfringens, is characterized primarily by abdominal cramps and diarrhoea, following an incubation period of 8 to $16 \mathrm{~h}$ [13]. This type of the disease is generally associated with the ingestion of bacteria producing toxins $[14,15]$. 
Although $B$. cereus is generally considered to be mainly associated with gastrointestinal disorders and severe eye infections, it is also an opportunistic human pathogen associated with a multitude of other local and systemic infections such as parodontitis, necrotising infections, endocarditis, nosocomial acquired bacteremia, osteomyelitis, sepsis, liver abscess, pneumonia and meningitis, particularly in postsurgical patients, immunosuppressed individuals, intravenous drug abusers and neonates [16-19]. However, despite the increasing frequency with which such non gastrointestinal diseases are being reported, there is still little recognition and appreciation of the role of $B$. cereus in these serious, and frequently fatal, clinical infections in humans.

In early stationary phase, $B$. cereus produces several compounds (degradation enzymes, cytotoxic factors and cell-surface proteins) that might contribute to virulence [20-26], and the illnesses associated with this organism are probably mediated by the synergistic effects of a number of virulence products. These products, known to accumulate only during stationary phase when high bacterial densities are reached, include two enterotoxic complexes (haemolysin BL (HBL) and non-haemolytic enterotoxin (NHE)), several phospholipases-C, a collagenase and various haemolysins/cytolysins (HlyI, HlyII, HlyIII and HlyIV) [13].

Most of these proteins are active against erythrocytes, and could therefore be defined as haemolysins and most $B$. cereus and B. thuringiensis strains form large, but distinct haemolytic halos when grown on human or sheep blood agar plates (Figure 1). HBL and NHE are homologous three-component pore-forming toxins inducing cell lysis in various eukaryotic cells [7,27]. The crystal structure of $\mathrm{HblB}$ and the modeled 3D structure of the other components show homology to the 3D structure of the pore-forming haemolysin cytolysin A (ClyA) from the Gram-negative enteric pathogen Escherichia coli [28]. HBL displays a unique ring-shaped haemolytic type (HT) in gel diffusion assays (haemolytic type $\mathrm{H}$ in Figure 1). NHE was originally described as having no haemolytic activity, accounting for its designation as "non-haemolytic" enterotoxin. However, NHE has also been shown, more recently, to be haemolytic towards erythrocytes from several mammalian species [28]. HBL and NHE have already been described and reviewed in detail elsewhere [13,29], and will not be addressed in this review.

$B$. cereus may also cause haemolysis by the combined/synergistic action of phosphatidylcholinespecific phospholipase $\mathrm{C}$ (PC-PLC) and sphingomyelinase (SPH), which form a biological complex known as cereolysin $\mathrm{AB}$ (CerAB) [30]. This membrane-disrupting complex specifically hydrolyses sphingomyelin in the intact erythrocyte membranes, causing erythrocyte haemolysis. The molecular properties of cereolysin $\mathrm{AB}$ result in haemolysis through enzymatic degradation of the cell membrane, but not by pore formation, and are therefore, beyond the scope of this review.

This review will therefore focus on the four other pore-forming haemolysins produced by B. cereus: haemolysin I or cereolysin O, haemolysin II, haemolysin III and haemolysin IV or CytK, as it is more commonly known. 
Figure 1. Haemolytic types (HT) for B. cereus and B. thuringiensis strains isolated from small soil samples. Haemolytic activity was determined at $30{ }^{\circ} \mathrm{C}$ on sheep blood agar plates. All 198 strains were plated on blood agar at the same time and compared after $15 \mathrm{~h}$. The haemolytic activity of each strain was estimated twice, and each replicate was classified "blind" with respect to the previous one. Nine different haemolytic types (A to I) were identified among the 198 strains [31].

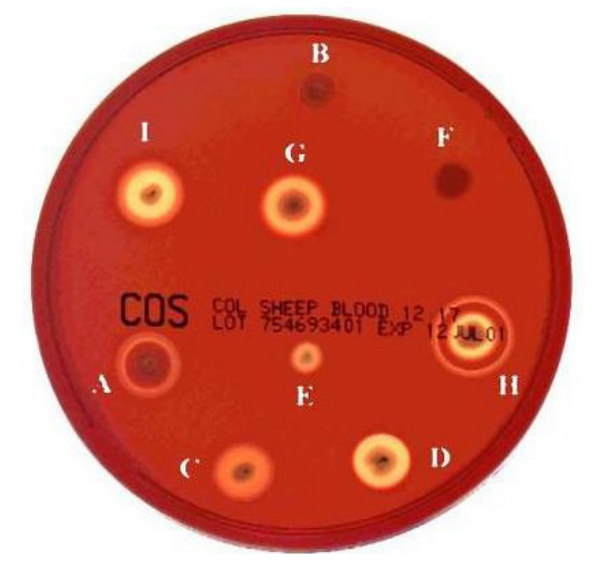

\section{Haemolysin I (Cereolysin O)}

\subsection{Genomic and Structural Features}

Haemolysin I was first described in 1967 [32], and was referred to as cereolysin O (CLO) in B. cereus, thuringiolysin O (TLO) in B. thuringiensis and anthrolysin O (ALO) in B. anthracis [33]. These proteins are very similar, with $98 \%$ identical amino-acid sequences [34]. CLO is a heat-labile protein whose haemolytic activity is inhibited by cholesterol $(<10 \mu \mathrm{g} / \mathrm{mL})$ and neutralized by anti-streptolysin-O globulins from hyperimmune horse serum [32,35]. CLO also shows 57\%-68\% amino acid similarity to perfringolysin-O (PFO) and streptolysin-O from Clostridium perfringens and Streptococcus pyogenes, respectively [36]. Haemolysin I, produced by B. cereus, can therefore be considered to belong to the cholesterol-dependent cytolysin (CDC) family (formerly known as thiol-activated cytolysins) and much about the structure and function of this molecule can be inferred from information available for the other members of the family [36]. There are a number of detailed reviews on this toxin family that consists of over 25 members that are produced by many different species of Gram-positive bacterial pathogens [37,38]. These toxins consist of a single polypeptide chain with a molecular weight of $50 \mathrm{kDa}$ to $80 \mathrm{kDa}$. The amino-acid sequences of the proteins of this family have an overall pairwise sequence identity of $40 \%$ to $70 \%$ that is distributed relatively evenly over the entire sequence of each molecule, suggesting they all have similar activities and 3D structures. These toxins also contain a highly conserved tryptophan-rich sequence (ECTGLAWEWWR) of 11 residues (an undecapeptide) in domain 4, close to the $C$-terminus, which participates in the binding of some CDCs to cholesterol-rich membranes [39]. The CDC toxins disrupt cell membranes, by forming large pores, up to $30 \mathrm{~nm}$ in diameter. In each case, the cytolytic activity of the CDC specifically requires the presence of cholesterol in membranes and does not seem to depend on any other specific cell-surface receptor. CDCs are, therefore, able to lyse the cytoplasmic membranes of almost all animal cells [37]. The entire crystal structure of a soluble monomer of PFO, 
the prototype of this toxin family, was determined in 1997 to a resolution of $2.7 \AA$ (Figure 2) and shown to be a $\beta$-sheet-rich, four-domain protein [40]. The monomer is folded into four discontinuous domains, forming an elongated mushroom-shaped molecule. The crystal structure of a second member of the CDC family, the intermedilysin (ILY), secreted by Streptococcus intermedius, has also been determined to a resolution of $2.6 \AA$ [41], and more recently, the crystal structure of the soluble state of ALO was solved, in a pre-pore conformation, to a resolution of $3.1 \AA$ [42]. The structural comparison of PFO, ILY and ALO revealed that the three-dimensional structures are well conserved and that the three proteins adopt a similar characteristic four-domain architecture, in which domain 4 is involved in membrane recognition, domain 3 is involved in $\beta$-sheet insertion, and domain 2 is the hinge region that undergoes a large conformational change. The putative membrane-binding domain 4 comprises the last $110 C$-terminal residues, including the conserved tryptophan-rich undecapeptide. In addition, three other short hydrophobic loops, L1, L2 and L3, flanking the undecapeptide at the tip of domain 4, have been shown to insert into the membrane surface and to anchor the CDC to the membrane [43]. The structure and molecular mechanism of several other CDCs are now also relatively well characterized. Pore forming by CDCs involves oligomerisation and the assembly of soluble monomers into a ring-shaped pre-pore, which undergoes a conformational change for insertion into the membrane, to form a large amphipathic transmembrane $\beta$-barrel structure [44].

Figure 2. Structure of the Perfringolysin $\mathrm{O}$ molecule shown in ribbon representation. Reproduced with permission from [40].

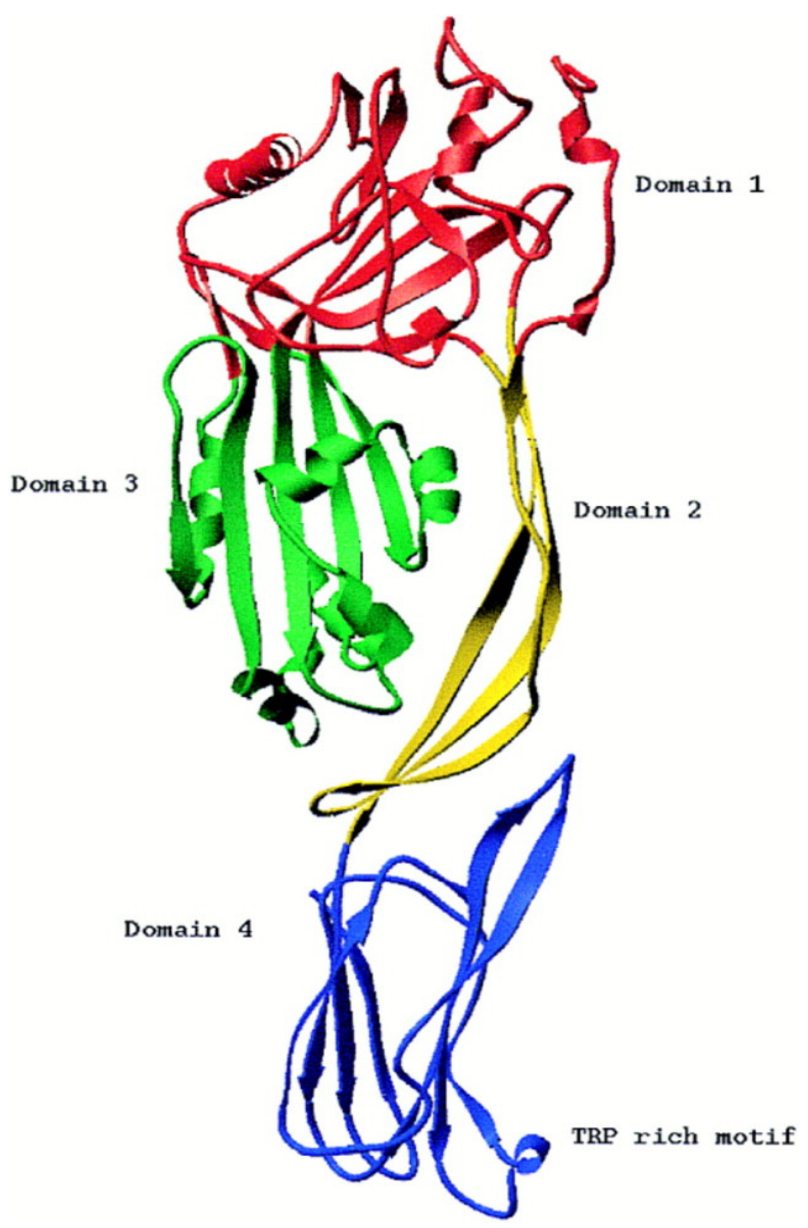




\section{2. $C L O$ in Virulence}

CDCs are cytolytic proteins produced by diverse Gram-positive bacteria. They can lyse or permeabilize host cells or intracellular organelles during infection. CDCs can also lyse various types of cells, including erythrocytes, in vitro. The best known members of this family are listeriolysin $\mathrm{O}$, perfringolysin and pneumolysin $\mathrm{O}$, produced by Listeria monocytogenes, $C$. perfringens and $S$. pyogenes, respectively. For L. monocytogenes, which releases its listerolysin O into host phagocytic cells, this protein has been shown to be important for virulence and essential for cellulosome escape and the intracellular multiplication of the bacterium [45]. In extracellular human pathogens, such as $C$. perfringens, which releases perfringolysin $\mathrm{O}$ into the extracellular environment, the toxin disrupts plasma membranes, causing cell death by necrosis. In B. anthracis, the recombinant ALO (rALO) purified from $E$. coli is extremely active against human erythrocytes [33]. In 2006, Mosser and Rest showed that ALO killed human monocytes, neutrophils, macrophages and lymphocytes, providing support for the notion that ALO is one of the virulence factors of B. anthracis [46]. B. cereus CLO is lethal when injected intravenously $(1-2 \mu \mathrm{g})$ into mice and is haemolytic at concentrations as low as $1 \mathrm{ng} / \mathrm{mL}$ [32]. CLO also induces the release of lactate dehydrogenase from retinal tissue in vitro, suggesting that it may exacerbate the necrosis typical of $B$. cereus endophthalmitis [47]. More recently, Bourdeau et al. showed that the apical application of ALO decreased the barrier function of human polarized gut epithelial cells as well as increased intracellular calcium, which caused specific rearrangement of the tight junction protein occludin [42]. Given that B. anthracis spores can enter the host through the gastrointestinal (GI) route, and that the epithelial cell barrier is one of the major obstructions to infection in the GI tract, they proposed that ALO-induced increase of intracellular calcium to alter tight junction architecture could lead to movement of the vegetative anthrax bacteria, or other bacterial toxins, into the surrounding tissues. However, additional research is needed to evaluate the validity of this hypothesis. The haemolysin I of B. cereus sensu lato therefore seems to perform various functions during bacterial infection.

\subsection{Gene Regulation}

In B. cereus and B. thuringiensis, the expression of CLO and TLO is controlled by the transcriptional activator PlcR $[48,49]$. PlcR was originally identified as a transcriptional activator of $p l c A$, the gene encoding phosphatidylinositol-specific phospholipase C [50]. For activity, PlcR requires PapR, a peptide expressed as a propeptide under the control of PlcR, which is exported out of the cell, processed to generate an active heptapeptide, and re-imported into the bacterial cell through the OppABCDF oligopeptide permease system (Figure 3) [51,52]. The PlcR/PapR system is now known to be the central transcriptional regulator for virulence genes in B. cereus at the onset of the stationary phase $[53,54]$. It controls the expression of a large regulon comprising at least 45 genes, including degradation enzymes, cell-surface proteins and toxins, most of which may be considered potential virulence factors [55].

In $B$. anthracis, the PlcR regulon is silent due to a nonsense mutation in the plcR gene that inactivates the PlcR protein. B. anthracis is, therefore, generally considered to be non-haemolytic. However, Shannon et al. demonstrated that ALO is expressed under certain growth conditions, 
suggesting that haemolysin I regulation in B. anthracis is different from that in $B$. cereus and B. thuringiensis [33]. However, the nature of the regulatory mechanisms and conditions promoting ALO expression in B. anthracis remain unknown.

Figure 3. Schematic representation of the transcriptional regulator PlcR and its cognate cell-cell signalling peptide PapR. The activity of PlcR depends on PapR, a secreted signalling peptide re-imported into the bacterial cell through the Opp system [51]. After its export, PapR is cleaved to a $C$-terminal heptapeptide active fragment that accumulates in the medium [52]. When high bacterial densities are reached, PapR concentration increases inside the bacterial cells, promoting its interaction with PlcR. The PapR-PlcR complex then binds to its DNA recognition site, the palindromic PlcR box, triggering a positive feedback loop that upregulates the expression of a regulon of 45 genes encoding proteins that are essentially secreted or bound or attached to cell wall structures at the interface between the bacterial cell and its environment [55]. These proteins are likely to be involved in host tissue degradation or in protecting the bacterial cell from host immune defenses, and may act together to provide food supply. Ultimately, when the bacteria enter the sporulation process, $p l c R$ transcription, and consequently PlcR-regulated gene expression, is repressed by the sporulation key-regulator Spo0A.

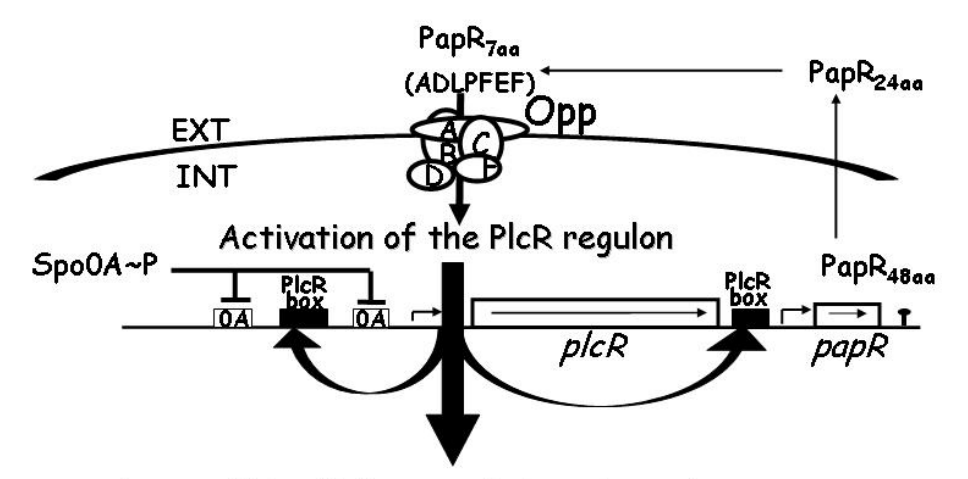

Extracellular PICR-controlled virulence factors

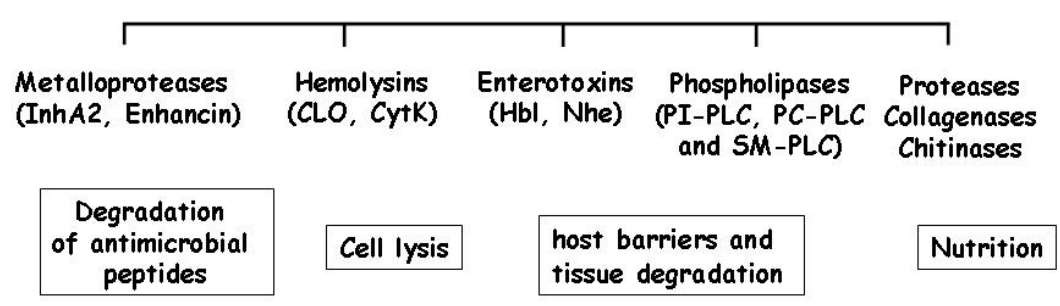

\section{Haemolysin II}

\subsection{Genomic and Structural Features}

In addition to CLO, early studies detected at least one B. cereus haemolysin, which was called haemolysin II (HlyII) [56]. HlyII activity is generally unaffected by cholesterol or anti-streptolysin $\mathrm{O}$ antibodies [57]. It is heat-labile and susceptible to proteolytic enzymes. The predicted 412-amino acid sequence of the HlyII precursor is reduced to a mature size of 381 amino acids (42.6 kDa) and this protein has a pI of 8.56 [58]. HlyII is an oligomeric $\beta$-barrel pore-forming toxin. This group of toxins 
includes the $\alpha$-toxin of Staphylococcus. aureus, the $\beta$-toxin of $C$. perfringens and the B. cereus cytotoxin $\mathrm{K}$ (CytK) [59,60]. HlyII displays 28\%-31\% amino-acid sequence identity to the staphylococcal $\alpha$-toxin, but it also has a 94 -amino acid $C$-terminal extension, absent from the other known members of the $\beta$-barrel pore-forming toxin family, which is not required for pore formation or haemolytic activity [61,62]. These $\beta$-barrel pore-forming toxins bind to membranes and form heptameric oligomers. Each monomer inserts a glycine-rich segment into the membrane to form the walls of a transmembrane pore. HlyII also contains a glycine-rich segment, suggesting a similar mechanism of membrane penetration, and has been shown to forms anion-selective channels with functional diameters of about $7 \AA$ in planar lipid bilayers (Figure 4) [59-62]. HlyII induces erythrocyte lysis, although it has been reported that HlyII has no specific receptor in erythrocytes [59]. In addition, HlyII induces the lysis of phagocytic cells (insect haemocytes, mouse macrophages, human monocytes and dendritic cells) but not epithelial cells $[63,64]$. The related $\alpha$-toxin of $S$. aureus appears to bind to the host cell receptor phosphocholine $[65,66]$ allowing the protein to accumulate locally in microdomains enriched in cholesterol and sphingolipids (lipid rafts). This suggests that certain cell types have high-affinity toxin-binding sites favouring toxin oligomerisation and thus stable membrane-anchored binding to target host cells [65]. The $\beta$-toxin from $C$. perfringens has also been shown to concentrate in lipid rafts [67].

Figure 4. Molecular model of the B. cereus haemolysin II heptameric pore. Molecular modeling was performed using the 3D structure of $\alpha$-hemolysin from $S$. aureus [60].

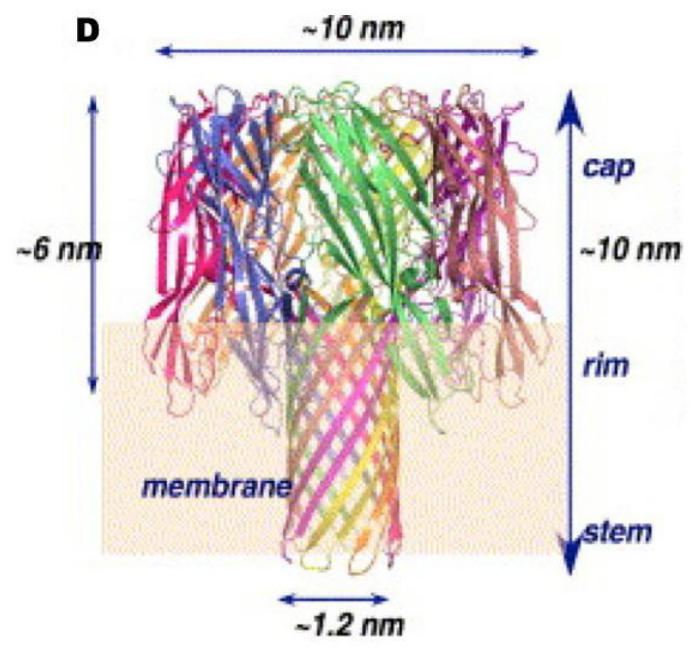

\subsection{Haemolysin II in Virulence}

HlyII is haemolytic and cytotoxic to human cell lines [59], but has not been implicated in the diarrhoea caused by $B$. cereus. It has been suggested that its lack of contribution to diarrhoea results from a trypsin digestion site in the B-loop constituting the transmembrane domain of the toxin, resulting in inactivation by trypsin in the small intestine $[8,13]$, as observed for the $\beta$-toxin of C. perfringens [68], but this remains to be tested experimentally. It has recently been shown that HlyII accumulates in high oxidation-reduction potential (ORP) conditions, but not in low ORP conditions, suggesting that the regulation of HlyII secretion is redox-dependent [69]. As anoxic and low ORP conditions mimic the intestinal environment, HlyII is unlikely to be a virulence factor involved in 
gastrointestinal disease. However, it has been shown that HlyII is involved specifically in immune cell death by apoptosis $[62,63]$ and that it is produced in large amounts by clinical strains of human origin [15], strongly suggesting a role in opportunistic infections.

Non-gastrointestinal B. cereus infections are characterized by bacteremia, despite the accumulation of inflammatory cells at the site of infection [70], implying that the bacteria have developed a means to resist the activity of inflammatory cells and thus, of the host immune system. $B$. cereus can circumvent the host immune response, as $B$. cereus spores survive, germinate and multiply in contact with macrophages [71], eventually leading to the production of secreted toxins responsible for host cell death [63]. HlyII has been shown to be one of the toxins responsible for host cell death $[63,64]$. Indeed, HlyII has haemolytic properties against a broad range of erythrocytes [59]. Its haemolytic activity with rabbit blood cells is more than 15 times more potent than that of Staphylococcus $\alpha$-toxin [59,62]. In addition, HlyII induces pore formation in the membranes of various eukaryotic cells [59-61], and the apoptosis of host monocytes and macrophages in vivo, in a death receptor-dependent pathway (activation of caspase 8) [63]. The ability of HlyII to kill macrophages may account for the persistence and dissemination of $B$. cereus in the host. The induction of apoptosis by $B$. cereus may cause tissue damage and compromise the antimicrobial immune response, thereby promoting bacterial spread, leading to the associated signs and symptoms of disease. Expression of the Bacillus cereus hlyII gene in B. subtilis induces haemolysis and virulence in a crustacean infection model [72]. HlyII has also been shown to be involved in B. cereus virulence in insects and mice [62]. The important role of HlyII has been highlighted by the presence of the hlyII gene in several clinical isolates of B. cereus [15], although its distribution remains limited [73].

\subsection{Regulation of Expression of the hlyII Gene}

HlyII is one of the few secreted virulence factors of B. cereus that is not regulated by PlcR, the central transcriptional regulator for virulence genes in $B$. cereus, which is required for the transcription of $h b l$, nhe, clo and $c y t K$. Instead, it has been shown to be down-regulated by the specific transcriptional regulator HlyIIR [74,75] and by the global regulator Fur [76,77]. The hlyII and hlyIIR genes are present in the same chromosomal locus ( $\mathrm{Bc} 3523$ and $\mathrm{Bc}$ 3522, respectively, in the ATCC 14579 strain) but are not organized into an operon. In vitro analyses have shown that recombinant HlyIIR regulates $h l y I I$ expression by the specific binding of two dimers to a perfect $44 \mathrm{bp}$ inverted DNA repeat $(22 \mathrm{bp} \times 2)$ centred $48 \mathrm{bp}$ upstream from the hlyII transcription initiation site [78]. The crystal structure of HlyIIR contains a large internal hydrophobic cavity that could accommodate a ligand with a molecular mass of up to $500 \mathrm{Da}$, suggesting that cofactor-dependent activation is involved in the inhibition of hlyII expression [79]. It has been suggested that the binding of the appropriate ligand to HlyIIR could change the orientation of the DNA-binding domains, modifying the affinity of the ligand-bound form for the specific DNA site [79]. Consistently, glucose-6-phosphate, a carbon source that is commonly used and consumed by bacteria during their growth [80], binds directly to HlyIIR, increasing its capacity to bind to its DNA box upstream from the hlyII gene, thereby inhibiting its expression [75].

HlyII expression is also regulated by the ferric uptake regulator (Fur). The hlyII promoter contains a Fur binding site overlapping the transcription start site [81] and the binding of Fur to this Fur 
box competes with RNA polymerase binding to the hlyII promoter, thus interfering with hlyII expression [77]. The deletion of fur in B. cereus results in lower virulence in an insect infection model, demonstrating a link between virulence and iron metabolism [81]. It has consistently been shown that the hlyII gene is down-regulated by iron during bacterial infection [77].

Sugar and iron are crucial compounds for bacterial multiplication and, thus, for their capacity to colonise their hosts. As a model, we suggest that, when glucose is consumed by the bacteria and iron is sequestered by phagocytic cells as a natural host defence [82,83], the HlyIIR and Fur repressors become inactivated and hlyII expression is triggered. HlyII is then produced by the bacteria and secreted, triggering the death of haemocytes and macrophages [63]. The contents of the cells are then released into the environment, providing the bacteria with access to nutrients and allowing them to grow, and thus promoting a new cycle of hlyII gene inhibition/expression (Figure 5).

Figure 5. Model of the role and expression of hlyII during infection (A) As long as iron and glucose are abundant in the bacterial environment, glucose enters the bacteria as glucose 6P (blue rectangles) and binds HlyIIR (plain orange cross). Iron (purple circles) binds Fur (red ovals). These binding events promote the repressor activities of HlyIIR and Fur, leading to the HlyIIR- and Fur-based transcriptional repression of hlyII gene expression (B) By contrast, when glucose and iron become scarce, hlyII expression is activated. HlyII is then released into the environment and induces macrophage and erythrocyte lysis. The dead cells release their intracellular content, providing access to metabolites that are essential for bacterial growth [75].

A

Glucose and iron rich environment

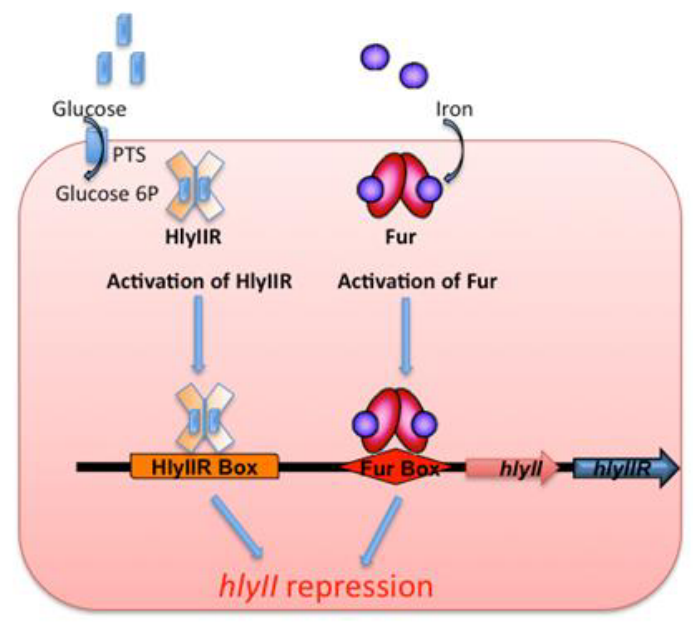

B

Glucose and iron limiting environment

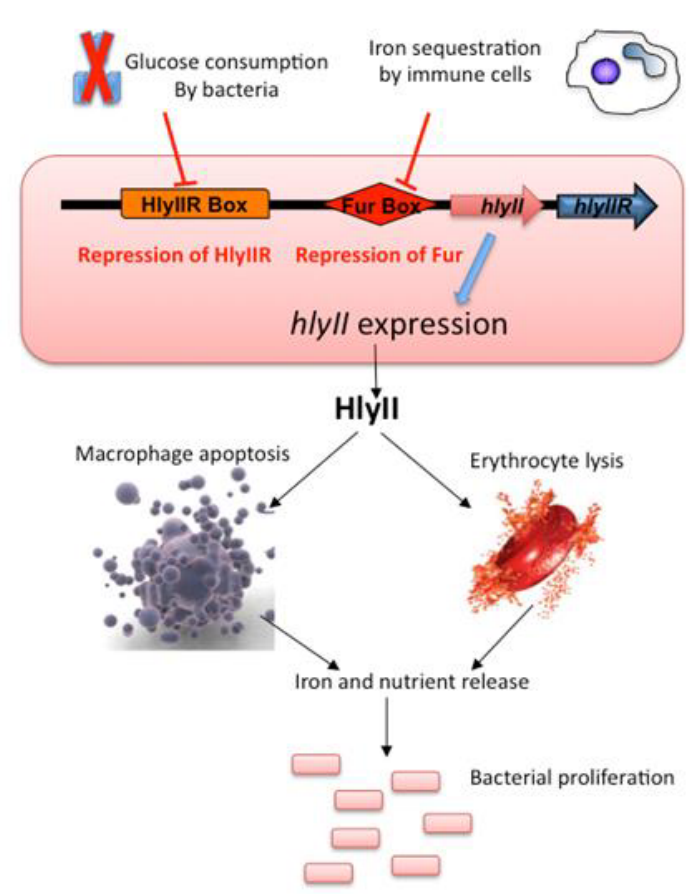




\section{Haemolysin III}

\subsection{Genomic and Structural Features}

Haemolysin III (HlyIII) is the least characterized haemolytic toxin from the B. cereus group. Its 657-nucleotide gene has been cloned and characterized in Escherichia coli. It is a heat labile protein whose haemolytic activity is not inhibited by cholesterol. The presumed precursor has a molecular weight of $24.4 \mathrm{kDa}$ and a $\mathrm{pI}$ of 9.42 . The toxin has not been purified, and it is unknown whether it is secreted by members of the $B$. cereus group. Its amino-acid sequence contains no obvious signal peptide for secretion [84]. However, membrane topology prediction using the TMpred program predicts that it does contain six 19- to 22-residue transmembrane segments typical of an integral membrane protein [85]. Moreover, 55\% of the protein consists of contiguous non-polar residues, suggesting that it would be unlikely to remain soluble in aqueous phase. Sequence analysis of the promoter region of hlyIII does not reveal the presence of the highly conserved palindromic region (TATGNAN ${ }_{4}$ TNCATA) that is the specific recognition target for PlcR activation indicating that expression of hlyIII is PlcR independent.

\subsection{HlyIII in Virulence}

The role of HlyIII in virulence has not been investigated in vivo and remains a matter of speculation. However, HlyIII induces a haemolytic phenotype on human blood agar when expressed in the heterologous host E. coli [86]. Osmotic protection experiments with E. coli lysates as the source of haemolysin have suggested that HlyIII forms transmembrane pores with an estimated diameter of 3-3.5 $\mathrm{nm}$ [86]. The toxin forms oligomeric pores in three steps: protein binding to the erythrocyte surface, monomer assembly to form the transmembrane pore, which finally leads to erythrocyte lysis. Binding and pore formation seem to be temperature dependent, whereas the lysis of erythrocytes is not [86].

\section{Haemolysin IV (Cytotoxin K)}

\subsection{Genomic and Structural Features}

Haemolysin IV, or CytK, is a $34 \mathrm{kDa}$ cytotoxic necrotic and haemolytic protein that was first partially characterized by Beecher et al. in 2000 [87]. The protein was then isolated, cloned and sequenced from the NVH 391/98 strain [8]. This strain was responsible for a severe food-borne outbreak of diarrhoeal disease in which several elderly people had bloody diarrhoea, three of whom died [8]. Four other similar strains have since been isolated, also mostly from food poisoning cases. These strains have been shown to form a robust and well separated cluster in the B. cereus group. Strain NVH $391 / 98$ is now the type strain of a newly validated species of the B. cereus group, Bacillus cytotoxicus [88].

The deduced amino-acid sequence of the protein is $37 \%$ identical to that of $B$. cereus haemolysin II described above and 30\% identical to that of the $\alpha$-hemolysin from $S$. aureus, suggesting that, from a structural point of view, CytK (like HlyII) belongs to the family of oligomeric $\beta$-barrel pore-forming toxins [8]. The $S$. aureus $\alpha$-haemolysin is one of the best characterized, pore-forming toxins. The 
structure of the pore created by a heptamer of this toxin has been determined to a resolution of $1.9 \AA$ [89]. These toxins are secreted in a soluble form, which is eventually converted into a transmembrane pore by the assembly of an oligomeric $\beta$-barrel, with the hydrophobic residues facing the lipids and the hydrophilic residues facing the lumen of the channel [90]. In 2004, Fagerlund and coworkers isolated, from B. cereus strain NVH 1230/88, a variant of CytK (CytK-2) with an amino-acid sequence $89 \%$ similar to that of the first CytK isolated (CytK-1). The differences between the CytK-1 and CytK-2 proteins were clustered in certain regions of the protein [91]. The strains harboring CytK-1 have recently been defined as a new species, B. cytotoxicus (see above), different from the B. cereus strains harboring the CytK-2 variant [92]. Both CytK proteins possess a Sec-type signal peptide, suggesting that CytK secretion occurs via the Sec translocation pathway. Consistently, intracellular accumulation and low levels of secretion of the toxin have been reported in cultures supplemented with sodium azide, an inhibitor of the SecA pathway [93].

\subsection{CytK in Virulence}

Little is known about the underlying mode of action of CytK at the cellular level. In vitro studies have revealed that this toxin forms pores that are weakly anion selective in pure phospholipid planar bilayers. The predicted minimum pore diameter for cytK is about 7 angströms [94], but the stoichiometry of oligomers and the structure of the pores remain unknown. Moreover, CytK can spontaneously form oligomers that are resistant to SDS but not boiling, a feature of other $\beta$-barrel pore-forming toxins. CytK-1 has been shown to be highly toxic to Vero and Caco-2 cells [94]. This suggests that the mode of action of this toxin involves the formation of pores in epithelial cells, causing fluid release and the destruction of the epithelial cells, resulting in necrosis [94]. The more common and more recently described variant of CytK, CytK-2, is also haemolytic and toxic to human intestinal Caco-2 cells and Vero cells. However, the CytK-2 protein from B. cereus NVH 1230/88 is only about a fifth as toxic to human intestinal Caco2 cells and Vero cells as the CytK-1 variant originally isolated from strain NVH 391-98 [91]. Both the CytK-1 and CytK-2 proteins form pores in planar lipid bilayers, but most of the channels observed with CytK-2 are of lower conductance than those created by CytK-1. Both variants of the CytK toxin are likely to contribute to the enterotoxicity of $B$. cereus strains. As $B$. cereus is not a homogeneous species, the food poisoning potential of a particular $B$. cereus strains is probably determined by a combination of adaptation traits, virulence factors and expression levels of toxin genes in a given strain $[95,96]$.

\subsection{Distribution of cytK Genes in B. cereus}

The occurrence of $c y t K$ in strains of $B$. cereus has been investigated. In 2002, Guinebretière et al. analyzed 37 food-poisoning and 25 food-borne $B$. cereus strains for the presence of $c y t K$ and the gene was found in less than $50 \%$ of the strains; cytK was detected in $73 \%$ of $B$. cereus isolates involved in diarrhoeal disease, but in only $37 \%$ of isolates from food not implicated in disease [97]. Similarly, in 2006, Wijnands et al. reported that the $c y t K$ gene was present in almost $50 \%$ of the 796 isolates tested, which originated from 182 different food samples [98]. In another recent study on 411 B. cereus and 205 B. thuringiensis strains, from food and soil, the cytK gene was detected in 365 $(89 \%)$ of the B. cereus and $172(84 \%)$ of the B. thuringiensis strains [99]. In 2006, a PCR-based 
detection system was developed and tested to provide insight into the distribution of $c y t K-1$ and $c y t K-2$ in the B. cereus group [92]. In a total of 391 B. cereus, from various phylogenetic groups (I to VII), most of the strains positive for $c y t K$ harbored the $c y t K-2$ variant, the $c y t K-1$ form being specific for the most distant group VII "B. cytotoxicus". The cytK-2 form was particularly frequent in mesophilic groups III and IV, whereas it was rare or absent from the psychrotolerant or moderately psychrotolerant groups (VI, II, and V). The cytK gene was absent from group I strains [100].

\subsection{Regulation of cytK Expression}

$c y t K$ gene expression is regulated by the quorum sensing PlcR/PapR system [55,95]. Sequence analysis of the promoter region of plcR-regulated genes has revealed the existence of a highly conserved palindromic region that acts as the specific recognition target for PlcR activation [55]. The cytK-1 promoter region of $B$. cereus strain NVH $391-98$ contains a putative PlcR box, TATGCAATTTCGCATA, diverging from the defined consensus recognition site, TATGNAN ${ }_{4}$ TNCATA (the underlined nucleotides are the most highly conserved in all the PlcR boxes), as initially defined for PlcR-controlled genes. In B. cereus strain ATCC 14579, the transcription of $c y t K-1$ starts at the onset of the stationary phase and peaks two hours later, as is the case for PlcR-controlled genes. Moreover, the expression of $c y t K-1$ is shut off in a PlcR-deficient mutant, indicating that its transcription is PlcR-dependent and that the PlcR box in the $c y t K-1$ promoter region is functional, despite a mismatch in the PlcR recognition site. As the $B$. cereus NVH 391-98 strain has been shown to synthesize larger amounts of $c y t K 1$ mRNA than other B. cereus strains [101], it is even possible that this mismatch in the plcR box accounts for the higher level of $c y t K-1$ expression in B. cytotoxicus. By contrast, another B. cereus strain, NVH 883/00, carrying the same cytK-1 gene displays very low levels of $c y t K-1$ expression and is not cytotoxic [102]. This suggests that variations in cytotoxicity between strains may be determined by differences in the level of expression of the toxin genes rather than by the presence of one or other of the two forms of the toxin or sequence polymorphism between the toxins. The $c y t K-1$ promoter regions in these strains were identical and the expression of PlcR was similar [101] indicating that differences in genetic backgrounds, between strains harbouring otherwise identical promoter and $c y t K$ gene sequences, may result in differences in $c y t K$ gene expression, leading to differences in CytK production. However, the exceptionally high level of cytK-1 expression of B. cytotoxicus NVH391-98 remains unexplained and may be due to as yet unidentified regulatory mechanisms [102]. The expression of $c y t K$ in B. cereus was recently investigated by developing a fluorescent B. cereus ATCC 14579 reporter strain containing the cyan fluorescent protein (CFPopt) gene under control of the $c y t K$ promoter. The authors found that toxin production was similar in the reporter and wild-type strains. However, only a small proportion of the reporter cells $(1 \%-2 \%)$ displayed fluorescence, and thus cyt $K$ expression, suggesting that toxin production originated from a small subpopulation of B. cereus ATCC 14579 in a homogeneous monoculture [103]. It remains unclear whether these results are specific to the ATCC14579 strain or can be generalized to a larger number of strains of different origins. Further studies are therefore required to unravel the complex regulatory pathway of $c y t K$ expression and regulation. 


\section{Conclusions}

In B. cereus, a large number of virulence genes are regulated in a cell density dependent manner by activating the expression of the PlcR regulon at the onset of stationary phase [54]. Activation of the $p l c R$ regulon results in the expression of genes with various functions and the secretion of many proteins that can have a negative effect on host cells, including enterotoxins, zinc metalloproteases, phospholipases, chitinases, collagenases, and two haemolysins: Clo and CytK (Figure 3). This ability to express many different toxins and virulence factors in a coordinated manner could allow the bacteria to increase its pathogenicity $[48,55]$. Haemolysins, which lyse erythrocytes, leading to the release of nutrients and iron-binding proteins, are among the most widely distributed toxins in pathogenic bacteria. Although it has been clearly established for a variety of other bacterial pathogens that haemolysins belonging to the cholesterol-dependent cytolysin (CDC) family or to the ß-barrel pore-forming toxin family contribute and are sometimes essential for pathogenesis, the exact role of these haemolysins (CLO, HlyII and CytK) in B cereus has not been completely elucidated. However, as pore formation is a major threat for cells, the cytotoxic properties of $B$. cereus haemolysins may enable the bacterium to damage epithelial cell layers, such as the intestinal barrier, and gain access to alternative sources of nutrients. In gastrointestinal anthrax, it is hypothesized that ALO may be the primary secreted virulence factor that affects bacterial movement through the epithelial cell barrier for systemic infection after spores are ingested and germinate on or within the epithelium of the gastrointestinal tract [42].

A deletion of plcR results in a strong reduction in virulence against both insect larvae and mice but does not abolish it totally [48], indicating that additional factors not regulated by PlcR contribute to virulence. Other regulators have been shown to also play a role in B. cereus virulence. For example, in an insect infection model, the virulence of a ferric iron uptake regulator (fur) null strain was found to be significantly attenuated, highlighting the essential role played by Fur in the virulence of this pathogen [81]. HlyII is one of the few known secreted virulence factors of $B$. cereus that does not appear to be regulated by PlcR. Instead, a Fur recognition sequence was found preceding the hlyII gene and Fur has been linked to the expression of hemolysin II, along with another gene, hlyIIR, subsequently discovered to be hlylI regulator [74]. Contrary to CLO and CytK, HlyII is unlikely to be a virulence factor involved in gastrointestinal disease. Instead, it has been shown that HlyII is involved in host macrophages death by apoptosis [63] and, as such, it may help to promote resistance to the host immune system. In vitro, the fourth haemolysin, HlyIII, was also shown to be a potent toxin that produces pores within the membrane of susceptible cells $[84,86]$. However, the in vivo toxicity of HlyIII has not yet been established and consequently, its role and contribution in B. cereus virulence remains unknown.

An in-depth investigation of the individual and synergistic effect of these toxins in combination with other known virulent determinants is now required. More attention must also be given to the stimuli (such as temperature, $\mathrm{PH}$, oxygen, redox potential, bile salts, and so on) potentially enhancing or reducing toxin activity in vivo and to the effects that the human gastro-intestinal tract have on the expression of these secreted virulence factors. 


\section{Conflict of Interest}

The authors declare no conflict of interest.

\section{References}

1. Guinebretière, M.H.; Thompson, F.L.; Sorokin, A.; Normand, P.; Dawyndt, P.; Ehling-Schulz, M.; Svensson, B.; Sanchis, V.; Nguyen-The, C.; Heyndrickx, M.; et al. Ecological diversification in the Bacillus cereus Group. Environ. Microbiol. 2008, 10, 851-865.

2. Ivanova, N.; Sorokin, A.; Anderson, I.; Galleron, N.; Candelon, B.; Kapatral, V.; Bhattacharyya, A.; Reznik, G.; Mikhailova, N.; Lapidus, A.; et al. Genome sequence of Bacillus cereus and comparative analysis with Bacillus anthracis. Nature 2003, 423, 87-91.

3. Rejasse, A.; Gilois, N.; Barbosa, I.; Huillet, E.; Bevilacqua, C.; Tran, S.; Ramarao, N.; Stenfors, A.L.P.; Sanchis, V. Temperature-dependent production of various PlcR-controlled virulence factors in Bacillus weihenstephanensis strain KBAB4. Appl. Environ. Microbiol. 2012, 78, 2553-2561.

4. Kolstø, A.B.; Tourasse, N.J.; Økstad, O.A. What sets Bacillus anthracis apart from other Bacillus species? Annu. Rev. Microbiol. 2009, 63, 451-476.

5. Anonymous. The community summary report on food-borne outbreaks in the European Union in 2007. EFSA J. 2009, doi:10.2903/j.efsa.2009.271r.

6. Hernaiz, C.; Picardo, A.; Alos, J.I.; Gomez-Garces, J.L. Nosocomial bacteremia and catheter infection by Bacillus cereus in an immunocompetent patient. Clin. Microbiol. Infect. 2003, 9, 973-975.

7. Kotiranta, A.; Lounatmaa, K.; Haapasalo, M. Epidemiology and pathogenesis of Bacillus cereus infections. Microbes Infect. 2000, 2, 189-198.

8. Lund, T.; de Buyser, M.L.; Granum, P.E. A new cytotoxin from Bacillus cereus that may cause necrotic enteritis. Mol. Microbiol. 2000, 38, 254-261.

9. Naranjo, M.; Denayer, S.; Botteldoorn, N.; Delbrassinne, L.; Veys, J.; Waegenaere, J.; Sirtaine, N.; Driesen, R.B.; Sipido, K.R.; Mahillon, J.; et al. Sudden death of a young adult associated with Bacillus cereus food poisoning. J. Clin. Microbiol. 2011, 49, 4379-4381.

10. Mahler, H.; Pasi, A.; Kramer, J.M.; Schulte, P.; Scoging, A.C.; Bär, W.; Krähenbühl, S. Fulminant liver failure in association with the emetic toxin of Bacillus cereus. N. Engl. J. Med. 1997, 336, 1142-1148.

11. Dierick, K.; van Coillie, E.; Swiecicka, I.; Meyfroidt, G.; Devlieger, H.; Meulemans, A.; Hoedemaekers, G.; Fourie, L.; Heyndrickx, M.; Mahillon, J. Fatal family outbreak of Bacillus cereus-associated food poisoning. J. Clin. Microbiol. 2005, 43, 4277-4279.

12. Ehling-Schulz, M.; Fricker, M.; Scherer, S. Bacillus cereus, the causative agent of an emetic type of food-borne illness. Mol. Nutr. Food Res. 2004, 48, 479-487.

13. Stenfors, A.L.P.; Fagerlund, A.; Granum, P.E. From soil to gut: Bacillus cereus and its food poisoning toxins. FEMS Microbiol. Rev. 2008, 32, 579-606.

14. Ramarao, N. Bacillus cereus: Caractéristiques et pathogénicité. EMC Biol. Méd. 2012, 7, 1-11. 
15. Cadot, C.; Tran, S.L.; Vignaud, M.L.; de Buyser, M.L.; Kolstø, A.B.; Brisabois, A.; Nguyen-Thé, C.; Lereclus, D.; Guinebretière, M.H.; Ramarao, N. InhA1, NprA and HlyII as candidates to differentiate pathogenic from non-pathogenic Bacillus cereus strains. J. Clin. Microbiol. 2010, 48, 1358-1365.

16. Bottone, E.J. Bacillus cereus, a volatile human pathogen. Clin. Microbiol. Rev. 2010, 23, 382-398.

17. Callegan, M.C.; Kane, S.T.; Cochran, D.C.; Novosad, B.; Gilmore, M.S.; Gominet, M.; Lereclus, D. Bacillus endophthalmitis: Roles of bacterial toxins and motility during infection. Invest. Ophthalmol. Vis. Sci. 2005, 46, 3233-3238.

18. Gray, J.; George, R.H.; Durbin, G.M.; Ewer, A.K.; Hocking, M.D.; Morgan, M.E. An outbreak of Bacillus cereus respiratory tract infections on a neonatal unit due to contaminated ventilator circuits. J. Hosp. Infect. 1999, 41, 19-22.

19. Miller, J.M.; Hair, J.G.; Hebert, M.; Hebert, L.; Roberts, F.J., Jr; Weyant, R.S. Fulminating bacteremia and pneumonia due to Bacillus cereus. J. Clin. Microbiol. 1997, 35, 504-507.

20. Bouillaut, L.; Ramarao, N.; Buisson, C.; Gilois, N.; Gohar, M.; Lereclus, D.; Nielsen-Leroux, C. FlhA influences Bacillus thuringiensis PlcR-regulated gene transcription, protein production, and virulence. Appl. Environ. Microbiol. 2005, 71, 8903-8910.

21. Tran, S.L.; Guillemet, E.; Gohar, M.; Lereclus, D.; Ramarao, N. CwpFM (EntFM) is a Bacillus cereus potential cell wall peptidase implicated in adhesion, biofilm formation and virulence. J. Bacteriol. 2010, 192, 2638-2642.

22. Gilois, N.; Ramarao, N.; Bouillaut, L.; Perchat, S.; Aymerich, S.; Nielsen-Leroux, C.; Lereclus, D.; Gohar M. Growth-related variations in the Bacillus cereus secretome. Proteomics 2007, 7, 1719-1728.

23. Brillard, J.; Susanna, K.; Michaud, C.; Dargaignaratz, C.; Gohar, M.; Nielsen-Leroux, C.; Ramarao, N.; Kolstø, A.B.; Nguyen-the, C.; Lereclus, D.; Broussolle, V. The YvfTU two-component system is involved in plcR expression in Bacillus cereus. BMC Microbiol. 2008, doi:10.1186/1471-2180-8-183.

24. Ramarao, N.; Lereclus, D. Adhesion and cytotoxicity of Bacillus cereus and Bacillus thuringiensis to epithelial cells are FlhA and PlcR dependent, respectively. Microbes Infect. 2006, 8, 1483-1491.

25. Auger, S.; Ramarao, N.; Faille, C.; Fouet, A.; Aymerich, S.; Gohar, M. Biofilm formation and cell surface properties among pathogenic and non pathogenic strains of the Bacillus cereus group. Appl. Environ. Microbiol. 2009, 75, 6616-6618.

26. Guillemet, E.; Cadot, C.; Tran, S.L.; Guinebretière, M.H.; Lereclus, D.; Ramarao, N. The InhA metalloproteases of Bacillus cereus contribute concomitantly to virulence. J. Bacteriol. 2010, 192, 286-294.

27. Lindbäck, T.; Okstad, O.A.; Rishovd, A.L.; Kolstø, A.B. Insertional inactivation of $h b l C$ encoding the L2 component of Bacillus cereus ATCC 14579 haemolysin BL strongly reduces enterotoxigenic activity, but not the haemolytic activity against human erythrocytes. Microbiology 1999, 145, 3139-3146.

28. Fagerlund, A.; Lindbäck, T.; Storset, A.K.; Granum, P.E.; Hardy, S.P. Bacillus cereus Nhe is a pore forming toxin with structural and functional properties similar to ClyA (HlyE, SheA) family of haemolysins, able to induce osmotic lysis in epithelia. Microbiology 2008, 154, 693-704. 
29. Senesi, S.; Ghelardi, E. Production, secretion and biological activity of Bacillus cereus enterotoxins. Toxins 2010, 2, 1690-1703.

30. Gilmore, M.S.; Cruz-Rodz, A.L.; Leimeister-Wächter, M.; Kreft, J.; Goebel, W. A Bacillus cereus cytolitic determinant, cereolysin $\mathrm{AB}$, which comprises the phospholipase $\mathrm{C}$ and sphingomyelinase genes: Nucleotide sequence and genetic linkage. J. Bacteriol. 1989, 171, 744-753.

31. Vilas-Boas, G.; Sanchis, V.; Lereclus, D.; Lemos, M.V.; Bourguet, D. Genetic differentiation between sympatric populations of Bacillus cereus and Bacillus thuringiensis. Appl. Environ. Microbiol. 2002, 68, 1414-1424.

32. Bernheimer, A.W.; Grushoff, P. Cereolysin: Production, purification and partial characterization. J. Gen. Microbiol. 1967, 46, 143-150.

33. Shannon, J.G.; Ross, C.L.; Koehler, T.M.; Rest, R.F. Characterization of anthrolysin O, the Bacillus anthracis cholesterol-dependent cytolysin. Infect. Immun. 2003, 71, 3183-3189.

34. Johnson, M.K.; Geoffroy, C.; Alouf, J.E. Binding of cholesterol by sulfhydryl-activated cytolysins. Infect. Immun. 1980, 27, 97-101.

35. Bernheimer, A.W.; Grushoff, P. Extracellular hemolysins of aerobic sporogenic Bacilli. J. Bacteriol.1967, 93, 1541-1543.

36. Alouf, J.E.; Billington, S.J.; Jost, B.H. Repertoire and General Features of the Family of Cholesterol-Dependent Cytolysins. In The Comprehensive Sourcebook of Bacterial Protein Toxins, 3rd ed.; Alouf, J.E., Popoff, M.R., Eds.; Academic Press: London, UK, 2005; pp. 643-658.

37. Palmer, M. The family of thiol-activated, cholesterol-binding cytolysins. Toxicon 2001, 39, 1681-1689.

38. Shatursky, O.; Heuck, A.P.; Shepard, L.A.; Rossjohn, J.; Parker, M.W.; Johnson, A.E.; Tweten, R.K. The mechanism of membrane insertion for a cholesterol-dependent cytolysin: A novel paradigm for pore-forming toxins. Cell 1999, 99, 293-299.

39. Jacobs, T.; Cima-Cabal, M.D.; Darji, A.; Méndez, F.J.; Vázquez, F.; Jacobs, A.A.; Shimada, Y.; Ohno-Iwashita, Y.; Weiss, S.; de los Toyos, J.R. The conserved undecapeptide shared by thiol-activated cytolysins is involved in membrane binding. FEBS Lett. 1999, 459, 463-466.

40. Rossjohn, J.; Feil, S.C.; McKinstry, W.J.; Tweten, R.K.; Parker, M.W. Structure of a cholesterol-binding, thiol-activated cytolysin and a model of its membrane form. Cell 1997, 89, 685-692.

41. Polekhina, G.; Giddings, K.S.; Tweten, R.K.; Parker, M.W. Insights into the action of the superfamily of cholesterol-dependent cytolysins from studies of intermedilysin. Proc. Natl. Acad. Sci. USA 2005, 102, 600-605.

42. Bourdeau, R.W.; Malito, E.; Chenal, A.; Bishop, B.L.; Musch, M.W.; Villereal, M.L.; Chang, E.B.; Mosser, E.M.; Rest, R.F.; Tang, W.J. Cellular functions and X-ray structure of anthrolysin O, a cholesterol-dependent cytolysin secreted by Bacillus anthracis. J. Biol. Chem. 2009, 284, 14645-14656

43. Soltani, C.E.; Hotze, E.M.; Johnson, A.E.; Tweten, R.K. Specific protein-membrane contacts are required for prepore and pore assembly by a cholesterol-dependent cytolysin. J. Biol. Chem. 2007, 282, 15709-15716. 
44. Dang, T.X.; Hotze, E.M.; Rouiller, I.; Tweten, R.K.; Wilson-Kubalek, E.M. Prepore to pore transition of a cholesterol-dependent cytolysin visualized by electron microscopy. J. Struct. Biol. 2005, 150, 100-108.

45. Vazquez-Boland, J.A.; Kuhn, M.; Berche, P.; Chakraborty, T.; Domínguez-Bernal, G.; Goebel, W.; González-Zorn, B.; Wehland, J.; Kreft, J. Listeria pathogenesis and molecular virulence determinants. Clin. Microbiol. Rev. 2001. 14, 584-640.

46. Mosser, E.M.; Rest, R.F. The Bacillus anthracis cholesterol-dependent cytolysin, Anthrolysin O, kills human neutrophils, monocytes and macrophages. BMC Microbiol. 2006, doi:10.1186/1471-2180-6-56.

47. Beecher, D.J.; Olsen, T.W.; Somers, E.B.; Wong, A.C. Evidence for contribution of tripartite hemolysin $\mathrm{BL}$, phosphatidylcholine-preferring phospholipase $\mathrm{C}$, and collagenase to virulence of Bacillus cereus endophthalmitis. Infect. Immun. 2000, 68, 5269-5276.

48. Agaisse, H.; Gominet, M.; Okstad, O.A.; Kolstø, A.B.; Lereclus, D. PlcR is a pleiotropic regulator of extracellular virulence factor gene expression in Bacillus thuringiensis. Mol. Microbiol. 1999, 32, 1043-1053.

49. Gohar, M.; Økstad, O.A.; Gilois, N.; Sanchis, V.; Kolstø, A.B.; Lereclus, D. Two-dimensional electrophoresis analysis of the extracellular proteome of Bacillus cereus reveals the importance of the PlcR regulon. Proteomics 2002, 2, 784-791.

50. Lereclus, D.; Agaisse, H.; Gominet, M.; Salamitou, S.; Sanchis, V. Identification of a Bacillus thuringiensis gene that positively regulates transcription of the phosphatidylinositol-specific phospholipase $\mathrm{C}$ gene at the onset of the stationary phase. $J$. Bacteriol. 1996, 178, 2749-2756.

51. Gominet, M.; Slamti, L.; Gilois, N.; Rose, M.; Lereclus, D. Oligopeptide permease is required for expression of the Bacillus thuringiensis plcR regulon and for virulence. Mol. Microbiol. 2001, 40, 963-975.

52. Bouillaut, L.; Perchat, S.; Arold, S.; Zorrilla, S.; Slamti, L.; Henry, C.; Gohar, M.; Declerck, N.; Lereclus, D. Molecular basis for group-specific activation of the virulence regulator PlcR by PapR heptapeptides. Nucleic Acids Res. 2008, 36, 3791-3801.

53. Lereclus, D.; Agaisse, H. Toxin and Virulence Gene Expression in Bacillus thuringiensis. In Entomopathogenic Bacteria: From Laboratory to Field Application; Charles, J.F., Delécluse, A., Nielsen-Leroux, C., Eds.; Kluwer Academic Publishers: Dordrecht, The Netherlands, 2000; pp. 127-142.

54. Slamti, L.; Lereclus, D. A cell-cell signaling peptide activates the PlcR virulence regulon in bacteria of the Bacillus cereus group. EMBO J. 2002, 21, 4550-4559.

55. Gohar, M.; Faegri, K.; Perchat, S.; Ravnum, S.; Økstad, O.A.; Gominet, M.; Kolstø, A.B.; Lereclus, D. The PlcR virulence regulon of Bacillus cereus. PLoS One 2008, 3, e2793.

56. Coolbaugh, J.C.; Williams, R.P. Production and characterization of two hemolysins of Bacillus cereus. Can. J. Microbiol. 1978, 24, 1289-1295.

57. Sinev, M.A.; Budarina, Z.I.; Gavrilenko, I.V.; Tomashevski1̌, A.I.; Kuzmin, N.P. Evidence of the existence of hemolysin II from Bacillus cereus: Cloning the genetic determinant of hemolysin II. Mol. Biol. 1993, 27, 1218-1229. 
58. Baida, G.; Budarina, Z.I.; Kuzmin, N.P.; Solonin, A.S. Complete nucleotide sequence and molecular characterization of hemolysin II gene from Bacillus cereus. FEMS Microbiol. Lett. 1999, 180, 7-14.

59. Andreeva, Z.; Nesterenko, V.F.; Yurkov, I.S.; Budarina, Z.I.; Sineva, E.V.; Solonin, A.S. Purification and cytotoxic properties of Bacillus cereus hemolysin II. Prot. Express. Purif. 2006, 47, 186-193.

60. Andreeva, Z.I.; Nesterenko, V.F.; Fomkina, M.G.; Ternovsky, V.I.; Suzina, N.E.; Bakulina, A.Y.; Solonin, A.S.; Sineva, E.V. The properties of Bacillus cereus hemolysin II pores depend on environmental conditions. Biochem. Biophys. Acta 2007, 1768, 253-263.

61. Andreeva-Kovalevskaya, Z.I.; Solonin, A.S.; Sineva, E.V.; Ternovsky, V.I. Pore-forming proteins and adaptation of living organisms to environmental conditions. Biochemistry 2008, 73, 1473-1492.

62. Miles, G.; Bayley, H.; Cheley, S. Properties of Bacillus cereus hemolysin II: A heptameric transmembrane pore. Protein Sci. 2006, 11, 1813-1824.

63. Tran, S.L.; Guillemet, E.; Ngo-Camus, M.; Clybouw, C.; Puhar, A.; Moris, A.; Gohar, M.; Lereclus, D.; Ramarao, N. Hemolysin II is a Bacillus cereus virulence factor that induces apoptosis of macrophages. Cell. Microbiol. 2011, 13, 92-108.

64. Tran, S.L.; Puhar, A.; Ngo-Camus, M.; Ramarao, N. Trypan blue dye enters viable cells incubated with the pore-forming toxin HlyII of Bacillus cereus. PLoS One 2011, 6, e22876.

65. Valeva, A.; Hellmann, N.; Walev, I.; Strand, D.; Plate, M.; Boukhallouk, F.; Brack, A.; Hanada, K.; Decker, H.; Bhakdi, S. Evidence that clustered phosphocholine head groups serve as sites for binding and assembly of an oligomeric protein pore. J. Biol. Chem. 2006, 281, 26014-26021.

66. Liang, X.; Ji, Y. Involvment of alpha5beta1 integrin and TNF alpha in Staphylococcus aureus alpha toxin induced death of epithelial cells. Cell. Microbiol. 2007, 9, 1809-1821.

67. Nagahama, M.; Hayashhi, S.; Morimitsu, S.; Sakurai, J. Biological activities and pore formation of Clostridium perfringens beta toxin in HL 60 cells. J. Biol. Chem. 2003, 278, 36934-36941.

68. Granum, P.E. Clostridium perfringens toxins involved in food poisoning. Int. J. Food. Microbiol. 1990, 10, 101-111.

69. Clair, G.; Roussi, S.; Armengaud, J.; Duport, C. Expanding the known repertoire of virulence factors produced by Bacillus cereus through early secretome profiling in three redox conditions. Mol. Cell. Proteomics 2010, 9, 1486-1498.

70. Hernandez, E.; Ramisse, F.; Ducoureau, J.P.; Cruel, T.; Cavallo, J.D. Bacillus thuringiensis subsp. konkukian (serotype H34) superinfection: case report and experimental evidence of pathogenicity in immunosuppressed mice. J. Clin. Microbiol. 1998, 36, 2138-2139.

71. Ramarao, N.; Lereclus, D. The InhA1 metalloprotease allows spores of the B. cereus group to escape macrophages. Cell. Microbiol. 2005, 7, 1357-1364.

72. Sineva, E.; Andreeva-Kovalevskaya, Z.I.; Shadrin, A.M.; Gerasimov, Y.L.; Ternovsky, V.I.; Teplova, V.V.; Yurkova, T.V.; Solonin, A.S. Expression of Bacillus cereus hemolysin II in Bacillus subtilis renders the bacteria pathogenic for the crustacean Daphnia magna. FEMS Microbiol. Lett. 2009, 299, 110-119.

73. Budarina, Z.I.; Sinev, M.A.; Mayorov, S.G.; Tomashevski, A.Y.; Shmelev, I.V.; Kuzmin, N.P. Hemolysin II is more characteristic of Bacillus thuringiensis than Bacillus cereus. Arch. Microbiol. 1994, 161, 252-257. 
74. Budarina, Z.I.; Nikitin, D.V.; Zenkin, N.; Zakharova, M.; Semenova, E.; Shlyapnikov, M.G.; Rodikova, E.A.; Masyukova, S.; Ogarkov, O.; Baida, G.E.; et al. A new Bacillus cereus DNA-binding protein, HlyIIR, negatively regulates expression of B. cereus haemolysin II. Microbiology 2004, 150, 3691-3701.

75. Guillemet, E.; Tran, S.L.; Cadot, C.; Rognan, D.; Lereclus, D.; Ramarao, N. Glucose 6P binds and activates HlyIIR to repress Bacillus cereus haemolysin hlyII gene expression. PLoS One 2013, 8, e55085.

76. Sineva, E.; Shadrin, A.; Rodikova, E.A.; Andreeva-Kovalevskaya, Z.I.; Protsenko, A.S.; Mayorov, S.G.; Galaktionova, D.Y.; Magelky, E.; Solonin, A.S. Iron regulates expression of Bacillus cereus hemolysin II via global regulator Fur. J. Bacteriol. 2012, 194, 3327-3335.

77. Tran, S.; Guillemet, E.; Lereclus, D.; Ramarao, N. Iron regulates Bacillus thuringiensis haemolysin hlyII gene expression during insect infection. J. Invert. Pathol. 2013, 113, 205-208.

78. Rodikova, E.A.; Kovalevskiy, O.V.; Mayorov, S.G.; Budarina, Z.I.; Marchenkov, V.V.; Melnik, B.S.; Leech, A.P.; Nikitin, D.V.; Shlyapnikov, M.G.; Solonin, A.S. Two HlyIIR dimers bind to a long perfect inverted repeat in the operator of the hemolysin II gene from Bacillus cereus. FEBS Lett. 2007, 581, 1190-1196.

79. Kovalevskiy, O.V.; Lebedev, A.A.; Surin, A.K.; Solonin, A.S.; Antson, A.A. Crystal structure of Bacillus cereus HlyIIR, a transcriptional regulator of the gene for pore-forming toxin hemolysin II. J. Mol. Biol. 2007, 365, 825-834.

80. Deutscher, J. The mechanisms of carbon catabolite repression in bacteria. Curr. Opin. Microbiol. 2008, 11, 87-93.

81. Harvie, D.R.; Vílchez, S.; Steggles, J.R.; Ellar, D.J. Bacillus cereus Fur regulates iron metabolism and is required for full virulence. Microbiology 2005, 151, 569-577.

82. Ratledge, C.; Dover, L.G. Iron metabolism in pathogenic bacteria. Annu. Rev. Microbiol. 2000, 54, 881-941.

83. Weinberg, E.D. Iron availability and infection. Biochim. Biophys. Acta 2009, 1790, 600-605.

84. Baida, G.E.; Kuzmin, N.P. Cloning and primary structure of a new hemolysin gene from Bacillus cereus. Biochim. Biophys. Acta 1995, 1264, 151-154.

85. Hofmann, K.; Stoffel, W. TMbase-A database of membrane spanning proteins segments. Biol. Chem. Hoppe-Seyler 1993, 374, 166.

86. Baida, G.E.; Kuzmin, N.P. Mechanism of action of hemolysin III from Bacillus cereus. Biochim. Biophys. Acta 1996, 1284, 122-124.

87. Beecher, D.J.; Wong, A.C. Cooperative, synergistic and antagonistic haemolytic interactions between haemolysin $\mathrm{BL}$, phosphatidylcholine phospholipase $\mathrm{C}$ and sphingomyelinase from Bacillus cereus. Microbiology 2000, 146, 3033-3039.

88. Guinebretiere, M.H.; Auger, S.; Galleron, N.; Contzen, M.; de Sarrau, B.; Debuyser, M.L.; Lamberet, G.; Fagerlund, A.; Granum, P.E.; Lereclus, D.; et al. Bacillus cytotoxicus sp. nov. is a novel thermotolerant species of the Bacillus cereus group occasionally associated with food poisoning. Int. J. Syst. Evol. Microbiol. 2013, 63, 31-40.

89. Song, L.H.; Hobaugh, M.R.; Shustak, C.; Cheley, S.; Bayley, H.; Gouaux, J.E. Structure of staphylococcal alpha hemolysin, a heptameric transmembrane pore. Science 1996, 274, 1859-1866. 
90. Menestrina, G.; Serra, M.D.; Prevost, G. Mode of action of beta-barrel pore-forming toxins of the staphylococcal alpha-hemolysin family. Toxicon 2001, 39, 1661-1672.

91. Fagerlund, A.; Ween, O.; Lund, T.; Hardy, S.P.; Granum, P.E. Genetic and functional analysis of the cytK family genes in Bacillus cereus. Microbiology 2004, 150, 2689-2697.

92. Guinebretiere, M.H.; Fagerlund, A.; Granum, P.E.; Nguyen-The, C. Rapid discrimination of cytK-1 and cytK-2 genes in Bacillus cereus strains by a novel duplex PCR system. FEMS Microbiol. Lett. 2006, 259, 74-80.

93. Fagerlund, A.; Lindback, T.; Granum, P.E. Bacillus cereus cytotoxins Hbl, Nhe and CytK are secreted via the Sec translocation pathway. BMC Microbiol. 2010, doi:10.1186/1471-2180-10-304.

94. Hardy, S.P.; Lund, T.; Granum, P.E. CytK toxin of Bacillus cereus forms pores in planar lipid bilayers and is cytotoxic to intestinal epithelia. FEMS Microbiol. Lett. 2001, 197, 47-51.

95. Ceuppens, S.; Rajkovic, A.; Heyndrickx, M.; Tsilia, V.; van de Wiele, T.; Boon, N.; Uyttendaele, M. Regulation of toxin production by Bacillus cereus and its food safety implications. Crit. Rev. Microbiol. 2011, 37, 188-213.

96. Kamar, R.; Gohar, M.; Jéhanno, I.; Réjasse, A.; Kallassy, M.; Lereclus, D.; Sanchis, V.; Ramarao, N. Pathogenic potential of B. cereus strains as revealed by phenotypic analysis. J. Clin. Microbiol. 2013, 51, 320-323.

97. Guinebretière, M.H.; Broussolle, V.; Nguyen-The, C. Enterotoxigenic profiles of food-poisoning and food-borne Bacillus cereus strains. J. Clin. Microbiol. 2002. 40, 3053-3056.

98. Wijnands, L.M.; Dufrenne, J.B.; Rombouts, F.M.; in 't Veld, P.H.; van Leusden, F.M. Prevalence of potentially pathogenic Bacillus cereus in food commodities in The Netherlands. J. Food Prot. 2006, 69, 2587-2594.

99. Ngamwongsatit, P.; Buasri, W.; Pianariyanon, P.; Pulsrikarn, C.; Ohba, M.; Assavanig, A.; Panbangred, W. Broad distribution of enterotoxin genes (hblCDA, nheABC, cytK, and entFM) among Bacillus thuringiensis and Bacillus cereus as shown by novel primers. Int. J. Food Microbiol. 2008, 121, 352-356.

100. Guinebretiere, M.H.; Velge, P.; Couvert, O.; Carlin, F.; Debuyser, M.L.; Nguyen-The, C. Ability of Bacillus cereus group strains to cause food poisoning varies according to phylogenetic affiliation (groups I to VII) rather than species affiliation. J. Clin. Microbiol. 2010, 48, 3388-3391.

101. Brillard, J.; Lereclus, D. Comparison of cytotoxin cytK promoters from Bacillus cereus strain ATCC 14579 and from a B. cereus food-poisoning strain. Microbiology 2004, 150, 2699-2705.

102. Fagerlund, A.; Brillard, J.; Fürst, R.; Guinebretière, M.H.; Granum, P.E. Toxin production in a rare and genetically remote cluster of strains of the Bacillus cereus group. BMC Microbiol. 2007, doi:10.1186/1471-2180-7-43.

103. Ceuppens, S.; Timmery, S.; Mahillon, J.; Uyttendaele, M.; Boon, N. Small Bacillus cereus ATCC 14579 subpopulations are responsible for cytotoxin K production. J. Appl. Microbiol. 2013, 114, 899-906.

(C) 2013 by the authors; licensee MDPI, Basel, Switzerland. This article is an open access article distributed under the terms and conditions of the Creative Commons Attribution license (http://creativecommons.org/licenses/by/3.0/). 